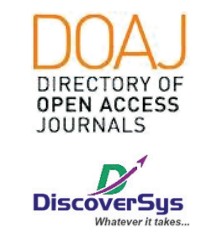

Published by DiscoverSys

\section{Trigger finger management, comparison of conservative and surgical treatment approach in hospital decision making: A case report}

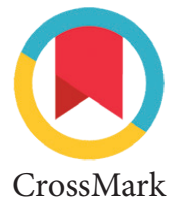

\author{
Anak Agung Ngurah Bayu Putra, ${ }^{1 *}$ Anak Agung Ngurah Ronny Kesuma ${ }^{2}$
}

\title{
ABSTRACT
}

Introduction: Trigger fingers are conditioned as the inability of the digit to move flex and extend caused by inflammation in the proximal edge of the flexor tendon pulley, such condition will have an impact on daily living activity and functional activity of person. Aim of this report is to give an overview regarding trigger finger clinical presentation with approach management in clinical setting.

Case Presentation: A 39-old male come to the policlinic with complaint stiffness in right middle finger, on physical examination finding the middle finger on the right hand is locking in flexed position, tenderness palpation over the $\mathrm{A} 1$ pulley.

Conclusion: Trigger finger is condition inability the digit can't move smoothly in flexed and extended. The management of trigger finger is based on Quinnell classification, after grading the treatment divided with conservative treatment or surgical treatment and both of treatment have success rate and complication rate.
${ }^{1}$ Faculty of Medicine, Warmadewa University, Bali-Indonesia ${ }^{2}$ Orthopaedic Departement, Wangaya Regional General Hospital, Denpasar, Bali-Indonesia
*Corresponding:

Anak Agung Ngurah Bayu Putra, Faculty of Medicine, Warmadewa University, Bali-Indonesia aangurahbayuputra@gmail.com

Received: 2018-09-24 Accepted: 2019-02-03 Published: 2019-04-01

Keywords: finger, locking, trigger, treatment.

Cite This Article: Putra, A.A.N.B., Kesuma, A.A.N.R. 2019. Trigger finger management, comparison of conservative and surgical treatment approach in hospital decision making: A case report. Intisari Sains Medis 10(1): 105-107. D0I: 10.1556/ism.v10i1.316

\section{INTRODUCTION}

Trigger finger is characterized by the inability of smoothly flex extend the digit and lead to loss of functional capacity of the hands, etiology by multicausal, commonly from repetitive movements and forcefull of using fingers lead to narrowing of fibrous layers of finger membranes. ${ }^{1,3,5}$ Study by Yadav et al. ${ }^{1}$ found trigger finger usually occur in dominant hand, middle-aged women more affected, and the thumb most frequently involved digit. Women to men ratio are 6:1 and right hand to left-hand ratio is 3:2. There is various method for the management of trigger fingers such as conservative and surgical treatment that has different rates of recovery, costs and post-treatment complaints. ${ }^{2}$ This case report aims to provide an overview of the choice of therapy from trigger finger between conservative and surgical treatment in a clinical condition.

\section{CASE PRESENTATION}

A 39-old male come to the policlinic with complain his right middle finger cant move exactly like the left side, he said that sometimes the finger was locking and can be released only by guide assistance from his left hand, it occurs from 3 months ago. On the first time he said that his finger just triggering sometimes but it worsening day by day and it makes the patient discomfort because he is a right-handed to do the working activity. Patient decided to see doctor to get better treatment. Patient says that he never did any treatment before. He doesn't have any chronic disease before and also doesn't have any allergies on food and medication. Vital sign examination found within normal limit, blood pressure $110 / 80 \mathrm{mmHg}$, respiration rate 18 times per minute, heart rate is 84 times per minute, and the temperature is $36.6^{\circ} \mathrm{C}$. On physical examination

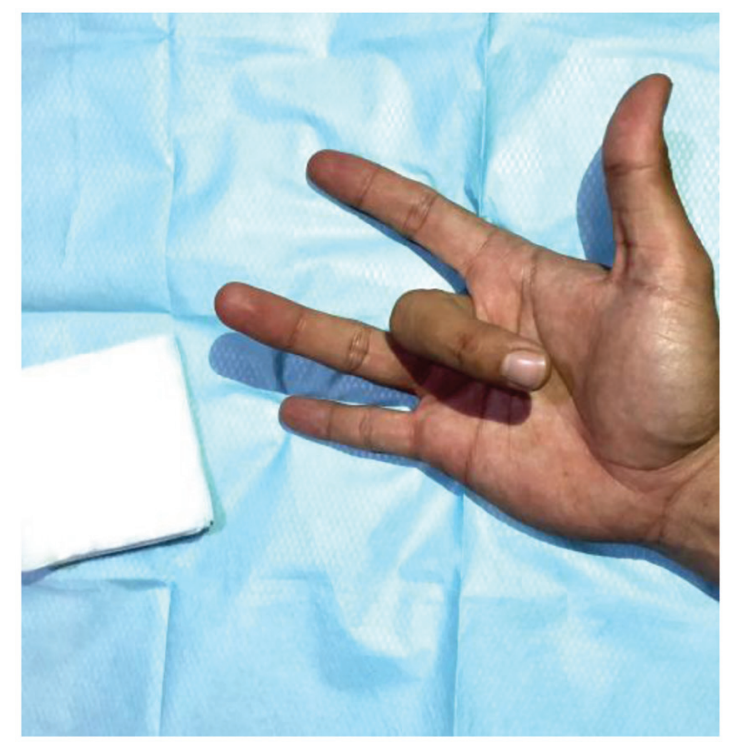

Figure 1 Locking of right middle finger in flexion position 
finding the middle finger on the right hand are locking in flexed position, tenderness palpation over the A1 pulley (Figure 1).

\section{DISCUSSION}

Trigger fingers are conditioned as the inability of the digit to move flex and extend caused by inflammation in the proximal edge of the flexor tendon pulley (A1 pulley). The surface anatomy of flexor tendons of each digit is run through pulley that creates fibro-osseous tunnel which keeps them close to the bone and joint during of movements.,10 In the fingers the A1 pulley as the underlying mechanical cause of trigger digit. The length of the A1 pulley is $6.3 \mathrm{~mm}$ in the central digits. The first early symptoms of trigger finger are the present of a nodule at the base of the finger (Notta's Nodule) with painful sensation, usually present in dominant hand with triggering or locking continued with tenderness, swelling, and loss of movement. ${ }^{1,3,4}$ Pain in the finger may be felt on finger flexion and may radiate to the proximal interphalangeal (PIP) and metacarpophalangeal (MTP). ${ }^{5,6}$ Most common cause trigger finger is overuse trauma of the hands from gripping with increased pull on the flexor tendon. The diagnostic is made by palpation and identification of localized tenderness and swelling of the volar tendon sheats, but ultrasound can be used when there are a clinical doubt and diagnostic can be made with hyperechoic lesion with cut-off thickness of $0.62 \mathrm{~mm}$ proposed to distinguish a disease from a healthy one, MRI for exclusion of secondary causes in younger patient and plain radiograph (in particular case) which is history of trauma. ${ }^{2,6}$ The severity of the triggers finger are graded by Quinnell classification. Grade 1 is mild crepitus in the non-triggering finger, grade 2 is no triggering but uneven finger movement, grade 3 is triggering is actively correctable, grade 4 is usually correctable by the others hand, grade 5 is the digit locked. ${ }^{1,2}$

In this case-patient was came to the policlinic with inability to move his middle finger it started from 3 months ago in his dominant hand, in the first week only triggering and worsening day by day. Physical examination finding is flexed position and tenderness palpitation over the A1 pulley. Patient diagnosed with right trigger finger digit 3 Quinnell classification grade 4 . The imaging examination was not performed because complaint and physical examination are obvious for diagnosis of trigger finger.

Management of trigger finger based on the guidelines divided by conservative treatment as corticosteroid injection and open surgery or percutaneous release the A1 pulley.,4 The goal of the therapy is to re-establish smooth, painless, and full range of motion in the affected digit. ${ }^{4}$ Conservative treatment according to Quinnell classification grade 1 triggers fingers requires only physiotherapy, NSAIDs, and corticosteroid injection at trigger point, grade 2 and grade 3 trigger finger is still a subject of debate. Grade $4 \& 5$ triggering is usually resistant to conservative treatment and requires surgical release., ${ }^{2,3}$ Castelannos et al. ${ }^{4}$ recommend corticosteroid injection treatment for all the patient with trigger finger were infiltrated by a mixture of $1.0 \mathrm{ml}(20 \mathrm{mg})$ paramethasone acetate (derivate from dexamethasone) and $1.0 \mathrm{ml}$ mepivacainechlorhydrate $2 \%$, injection is performed through the palmar approach with the needle inserted parallels to tendon fibers at the A1 pulley level, the needle was introduced directly into the flexor tendon only until the slight resistance was felt and as the patient to wiggle to check if the needle is in the correct position then do the injection. According to David et al. ${ }^{6}$ open surgical release is usually performed under local anesthesia and tourniquet control with a small skin incision made over the A1 pulley which is incised longitudinally and intraoperative active movement will asses adequacy of release and the proximal 3-4 $\mathrm{mm}$ of the A2 pulley also released $8 \%$ to correct any residual impingement. Study by Yadav et al. ${ }^{1}$ comparing percutaneous release and steroid injection in the treatment of trigger finger found that steroid injections for trigger finger has success rates of 50-92\% and open surgical release of the A1 pulley through a small palmar incision is a simple procedure with success rate is up to $100 \%$, however the complication rate is $7-28 \%$ have been reported.

The primary therapy on this patient based Quinnell classification grade 4 is surgical, which is to release the A1 pulley with open release surgery. ${ }^{78}$ The procedure was done under local anesthesia and the position are held on hyperextension, surface area is located in the halfway between proximal and distal palmar crease for the middle finger.

\section{CONCLUSION}

Trigger finger is condition inability the digit cant move smoothly in flexed and extended. The most common etiology of trigger fingers is overuse trauma on the hands such as movement handling the computer mouse, factory worker affects the muscles and ligament when they do for long time. The management of trigger finger is based on Quinnell classification, after grading the treatment divided with conservative treatment or surgical treatment and both of treatment have success rate and complication rate. 


\section{REFERENCES}

1. Yadav M, Sharma D, Kumar K, Yadav N. Comparison between percutaneous release and corticosteroids injection in the management of trigger digits. International Journal of Orthopaedics Sciences. 2017;3(3):21-26.

2. Aref HA, Fatemeh S, Hosein KM. Comparison between corticosteroids injection and surgery in the treatment of trigger finger. Journal of translational internal medicine. 2014;2(3):1-4.

3. Pecar M, Avdix D, Pecar D. Evaluation of the conservative treatment of trigger finger by local installation of corticosteroids. Journal of Health and Science. 2011;1(3):1-7.

4. Castellanos J, Mahamud M, Dominguez E, Amo PD, Izquierdo O, Fillat P. Long-term effectiveness of corticosteroids injection for trigger finger and thumb. J Hand Surg Am;2015;40:1-6.

5. Fowler JR, Ogrich L, Evangelista P, Schaffer AA. Assessing injection techniques in the treatment of trigger finger. Modern Pastic Surgery. 2012;2:83-86.
6. David M, Rangaraju M, Raine A. Acquired triggering of the fingers and thumb in adults. BMJ. 2017;359:j5285.

7. Akhtar S, Bradley MJ, Quinton Dn, Burke FD. Management and referral for trigger finger/thumb. BMJ. 2005;331:30-34.

8. Chang EY, Chen KC, Chung CB. MR imaging findings of trigger thumb. Skeletal Radiol. 2015;44:1201-1207.

9. Yang TH, Chen HC, Liu YC, Shih HH, Kuo LC, Cha S, et al. Clinical and pathological correlates of severity classification in trigger fingers based on computer-aided image analysis. Biomedical Engineering Online. 2014;13:1-12.

10. Hamid A, Triwono G. Finger Replantation in Sanglah General Hospital: Report of Five Cases and Literature Review. Bali Medical Journal. 2016;5(3):522-527. DOI: 10.15562/bmj.v5i3.339

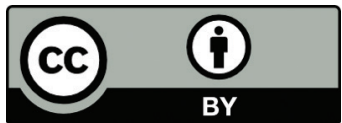

This work is licensed under a Creative Commons Attribution 